\title{
Chemoradiotherapy-induced Cochlear Toxicity
}

\author{
Leyla Topkan ${ }^{1}$, Huseyin Mertsoylu ${ }^{2}$, Ali Ayberk Besen², Ahmet Kucuk ${ }^{3}$, Ugur Selek ${ }^{4}$, Erkan \\ Topkan ${ }^{5}$ \\ ${ }^{1}$ Audiology Clinics, Adana City Treatment and Research Hospital, Adana, Turkey \\ ${ }^{2}$ Department of Medical Oncology, Baskent University Medical Faculty, Adana, Turkey \\ ${ }^{3}$ Clinics of Radiation Oncology, Mersin City Hospital, Mersin, Turkey \\ ${ }^{4}$ Department of Radiation Oncology, Koc University School of Medicine, Istanbul, Turkey \\ ${ }^{5}$ Department of Radiation Oncology, Baskent University Medical Faculty, Adana, Turkey \\ *Corresponding Author: Erkan Topkan, MD, \\ Department of Radiation Oncology, Baskent University Medical Faculty, 01120, Adana, Turkey.
}

\begin{abstract}
Radiation-induced sensorineural hearing loss (RI-SNHL) is a progressive and irreversible complication of radiotherapy (RT) or chemoradiotherapy (CRT) of brain or head and neck tumors. Onset and progression times of RI-SNHL may broadly vary depending on the RT technique, dose, and concurrent or adjuvant usage of ototoxic medications, such as cisplatin. Characteristically the high frequencies $(\geq 4 \mathrm{kHz})$ form the first affected range on a typical audiogram, which may be trailed by impairements in the lower hearing frequencies. RI-SNHL may adversely impact both the academic and social advancement in pediatric age and may deteriorate quality of life measures in all affected patients regardless of their age. Even if not eliminate all, in absence of a unequivocally proven medical treatment to avoid or alleviate the RI-SNHL, utilization of more advanced RT techniques, such as the intensity-modulated RT, and limiting the cochlea doses to $\leq 40-45$ Gy for RT alone, $<10$ Gy for concurrent RT and cisplatin, and $<10-12$ Gy for stereotactic radiosurgery applications may demonstrate valuable in minimizing the risk of SNHL development. Furthermore, as reactive oxygen species (ROS) are the essential introductory causatives in RT-induced damage via activating the apoptotic cascade in cochlear hair cells, hopefully the development of novel radioprotective agents with the ability to lessen ROS production may prove beneficial in reducing the cochlear damage, and therefore, RI-SNHL, in near future.
\end{abstract}

Keywords: Cochlea, ototoxicity, radiotherapy, chemoradiotherapy, cisplatin, prevention.

\section{Introduction}

Radiotherapy (RT) or chemoradiotherapy (CRT) are well established integral part of definitive organ preservation or postoperative adjuvant treatment of head and neck cancers (HNC), and brain-, brainstem-, and skull base tumors and (1). Because of the significantly enhanced survival times with more effective local and systemic treatments, the late complications of RT and systematic chemotherapeutics have been noted to be more frequently manifested in these patients, such as the late ototoxcity. Progressive and irreversible sensorineural hearing loss (SNHL) is relatively the commonest and most debilitating treatment related ototoxicity type which is mainly caused by the damage to the cochlea (the organ of hearing and balance) and/or acoustic branch of the vestibulocochlear nerve, which are located in close proximity or right inside the RT field in most HNC and brain tumors.

Present manuscript aims to focus on the diagnosis, clinics, pathophsiology, radiobiology, and treatment and/or prevention maneuvers of radiation-induced SNHL(RI-SNHL) with specific empahasis on the preventive related measures including the use of sophisticated RT techniques and dose constraints to the cochlea. 


\section{Hearing Process in Brief}

Recognizing the fact that it is undoubtedly more complex, the process of hearing is roughly divided into six basic steps:

1) To begin with, the sound waves approaching a particular side of the head travel along the external acoustic meatus and reach the tympanic membrane on that side.

2) The tympanic membrane collects the sound waves and vibrates in resonance to their frequencies between approximately 20 and 20,000 Hz. Vibration of tympanic membrane transfers the sound to the malleus, incus, and stapes bones and cause displacement of them in a vibrating manner, which in this way amplifies the incoming sound.

3) Because the liquids are not compressible and the rest of the cochlea is sheathed in bone, the stapes vibrating at the frequency of the sound arriving at the oval window creates pressure waves in the perilymph of the scala vestibuli.

4) The pressure waves created by the stapes travel through the perilymph of the scala vestibuli and scala tympani to reach the round window, where these waves distort the basilar membrane before reaching the round window of the scala tympani. The frequency of the sound determines the location of maximum distortion because of the regional differences in the width and flexibility of the basilar membrane along its length. Based on the laws of acoustical physics, the high frequency sounds with shortest wavelength vibrate the basilar membrane near the oval window, while the lower the frequency sounds with the longer the wavelength vibrates the farther regions of the basilar membrane, therefore determines the area of maximum distortion. Therefore, with these unique capabilities, it is imperative to note that the cochlea is an excellent frequency analyzer.

5) Hair cells are moved against the tectorial membrane by the vibrating zone of the affected basilar membrane, which prompts the displacement of the stereocilia with resultant opening of the ion channels in the plasma membranes of the hair cells of the spiral organ. The hair cells are depolarized by the influx of ions, leading to stimulation of sensory neurons by the release of neurotransmitters. In the spiral organ, the hair cells of are organized in several rows and are stimulated according to the intensity of the incoming sound. That, a very soft sound (less intense) stimulates only a couple of hair cells in a small portion of one row, while not only do these hair cells become more active but additional hair cells (first in the same and afterward in neighbouring rows) are stimulated as well, in parallel with the increments in the intensity of the incoming sound.

6) Lastly, the cell bodies of the bipolar sensory neurons that monitor the cochlear hair cells, which are located at the center of the bony cochlea (in the spiral ganglion), carry the information from the cochlea to the cochlear branch of vestibulocochlear nerve. Cochlear nerve than transfers the processed information to the cochlear nuclei of the medulla oblongata.From there, information ascends to the superior olivary nucleus of the pons and both inferior colliculi of the midbrain, where a number of responses to acoustic stimuli including the auditory reflexes that involve skeletal muscles of the head, face, and trunk are coordinated. Before reaching the cerebral cortex and the individual's awareness, ascending auditory sensations synapse in the medial geniculate nucleus of the thalamus. Than the projection fibers deliver the information to the auditory cortex of the temporal lobe over cortical labelled lines. Therefore, the auditory cortex contains a map of the spiral organ, implying that the low and high frequency sounds activate distinctive zones of the auditory cortex.

\section{Radiobiological Aspects of RI-SNHL}

Radiation is the emission and propagation of energy through space or a material medium. Simply, there are two kinds of radiation, namely particle- and electromagnetic radiation. Particle radiation is defined as the energy propagation by traveling corpuscles which has a definite rest mass and within limits have a definite momentum and defined position at any instant. Electromagnetic radiation, first described by Maxwell, implies for the mode of energy propagation such as light waves, heat waves, radio waves, microwaves, ultraviolet rays, and ionizing radiations including the $\mathrm{X}$ - and $\gamma$-rays.

The energy of ionizing radiation is conveyed in the form of photons, also called quantum, where quantum represents for the smallest unit of the energy of electromagnetic radiation. Principally, ionizing radiation may be classified as directly or indirectly ionizing. All of the charged particles are directly ionizing and carry adequate energy that is sufficient to cause direct biologic or chemical changes by disrupting the atomic 
structure. While, indirectly ionizing X-and $\gamma$-rays do not themselves lead to direct biologic or chemical changes in the tissue through which they pass, instead they give up their energy to produce fast-moving charged particles that in turn able to produce damage in the absorbing media.

At high energy levels, such as cobalt-60 units or linear accelerators, Compton process is the predominant interaction type between the incoming photon and the target tissue, in which the energetic photon ejects a loosely bound outer electron from the attacked atom by imparting a part of its energy to the electron. Low linear energy transferring $\mathrm{X}$ - and $\gamma$-rays mainly produces their actions via these fast moving electrons: indirect action of radiation, and constitute approximately $2 / 3$ of its all actions on tissue. In this interaction mode, radiation interacts with intra and extracellular molecules, particularly the $\mathrm{H}_{2} \mathrm{O}$ molecules which are the most abundant molecules in the living tissues. Consequences of this reaction lead to production of highly reactive free radicals (mainly hydroxyl radicals) with the diffusing capacity of relatively short distances in the cell. When the hydroxyl radical reach the deoxyribonucleic acid (DNA) it binds to the DNA and cause double-strand breaks. If not rapidly and accurately repaired, these breaks result in mitotic cell death, induction of apoptotic response by activation of p53 (guardian of the cell), or lengthened cell cycle arrest. The faith of the preferred pathway will depend on the cell type, severity of damage, and the integrity of p53. Although the rapidly proliferating tissues, such as the mucosa or skin, may react quickly and renew the injured tissue totally, in tissues with no self-proliferation capacity or functional progenitor units the result will be the total loss of organ function, such as the hair cells of the organ of Corti or the neurons of the spiral ganglion (2-4).

The damage initiated by free radicals has been postulated to propagate by the production of cytoplasmic reactive oxygen species (ROS) in the presence of $\mathrm{O}_{2}$, which are particularly damaging to the oxygen-rich mitochondria (5). Although the radiation-induced excess ROS production is comparably lower than those produced during normal oxidative metabolism processes and adds only a little to the total quantity, yet, it may reach levels sufficient enough to disrupt homeostasis and create oxidative stress in the cell (6). Accessible evidence demonstrated the additional stimulation of the nitric oxide synthase by radiation and formation of peroxynitrite anions as a result of its reaction with superoxide dismutase (7). Peroxynitrite anions are excessively reactive nitrogen species (RNS) which further damage cell membranes and DNA. Therefore, continuous production of ROS and RNS alone or together may promote and deepen the radiationinduced cell damage at long term (7).

In vitro evidence suggests that the non-proliferative cochlear hair cells die most likely by the activation of RT-induced apoptosis (8). RT-induced apoptosis may occur in two separate ways: p53 dependent and p53 independent pathways. In the p53 dependent apoptosis, sensation of the DNA injury activates the p53 with resultant cell cycle arrest to facilitate DNA repair process in tolerable injuries or activation of apoptotic pathways if the damage is irreversibly beyond the repair capacity (9). In one of the rare reports investigating the apoptosis in auditory hair cells, Low et al. (8) studied the post-RT apoptosis and ROS production in immature mice auditory hair cells, and showed that ROS production was increased in just $1 \mathrm{~h}$ after the RT while $72 \mathrm{~h}$ was needed to detect p53 activation. This finding is important by demonstration of the increased ROS production as a function of exposed dose and as a triggering factor for activation of p53 dependent apoptotic processes in the cochlear hair cells. The second probable cochlear damage pathway is the p53 independent pathway (sphyngomyelin-ceramide pathway), which becomes evident $24 \mathrm{~h}$ after RT-induced DNA damage in epithelial cells as a dose-dependent response involving the interaction of ROS with the cellular plasma membranes (10). Nonetheless, given their profoundly specialized and non-proliferative state, it is unlikely that the outer and inner hair cells of the organ of Corti or neurons of the spiral ganglion exhibit this pathway as a response to RT. On the other hand, the sphyngomyelin-ceramide pathway may be activated in the vascular endothelial cells of the stria vascularis with resultant p-53 independent apoptosis in the inner and outer hair cells, at least in the range of high-dose single fraction RT.

In summary, accessible radiobiologic data suggests that the main cells affected after fractionated RT are the inner and outer cells of the organ of Corti and to some degree the neurons of spiral ganglion, with p53 dependent apoptosis being the main and established pathway of cell death, and therefore development of RI-SNHL.

\section{Pathophysiology of RI-SNHL}

Despite the fact that Girden and Culler were the first to exhibit noteworthy increments in the hearing thresholds of irradiated dogs in 1933 (11), yet, the earliest experimental studies on the functions of the inner 
ear go back to 1905 with Ewald's first observations which demonstrated the diminished vestibular functions of irradiated pigeons. In another striking early investigation published in 1958, Kozlov revealed a 3.9 to 9.1 $\mathrm{dB}$ decline in the hearing of irradiated guinea pigs involving the all frequencies between the 0.5 to $8.0 \mathrm{kHz}$ (12).

An essential drawback of early experimental animal studies was that the animals were commonly exposed to single fraction large doses of radiation which might have been associated with morbidities far beyond the currently utilized conventionally fractionated clinical RT protocols. Single fraction large dose RT has been estimated to be much more lethal than the equivalent amount administered over time using appropriately fractionated protracted schemes (13). Recently, using a novel model mimicking human exposures, Miller et al. compared the effects of RT (70.75 Gy over 25 fractions) versus cisplatin-alone versus their combination in guinea pigs (14). Proposing the RT as the main causative of SNHL, the authors reported that the 5 of 6 animals in the RT alone arm developed severe SNHL in at least one ear in contrast with no significant SNHL in the cisplatin-alone arm.

\section{Radiation-induced Sensorineural Hearing Loss}

Radiotherapy either alone or combined with chemotherapy constitutes the backbone of multidisciplinary treatment of HNC, skull base, brain, brainstem, and cerebellopontine angle tumors both in adult and pediatric patients. As a result of the intricate and interconnected anatomy of this region, uni- or bilateral cochlea often unavoidably dwells within the high-dose region of conformal RT plans. Even though the cochlear dose may be reduced to some extent by using more sophisticated intensity-modulated RT (IMRT) and respecting the pre-specified dose constraints, yet, cochlea may still receive significant doses in many cases.

RI-SNHL, which manifests months or years after the completion of the RT in nearly 50\% (range: 4-90\%) of all patients, is probably the most serious RT-induced late toxicity of the head and neck region except for the tissue necrosis (15-17). RI-SNHL may occur as early as within 3 to 24 months after completing RT (median: 1.5-2 years), which is suggested to be relatively shorter in single fraction large dose SRS (median: 4 months) than the hypo- or conventionally fractionated RT schemes (18). Some studies also reported that hearing reduction/loss may suddenly occur just after the RT as a result of mechanistically different acute reactions $(19,20)$. One proposed mechanism explains the acute and sudden hearing loss as a consequence of the compression of the cochlear artery caused by SRS-induced edema (20). Another explanatory mechanism for the acute hearing deterioration proposes that the rapid formation of the post-RT free radical ions create a triggering effect for vasospasm of the stria vascularis which in turn dramatically decreases the cochlear blood flow (21) and cause hearing reduction/loss depending on the extent of ischemia.

Radiation-induced vascular endothelial damage is one of the causes accused of SNHL advancement $(22,23)$. Animal and human investigations have indicated alterations such as bleeding at inner ear spaces and edema at membranous labyrinth, internal and external hair cell loss at organ of Corti, and atrophic degeneration of the stria vascularis, spiral ganglion cells, and cochlear nerve $(24,25)$. Inflammation and edema prompted by RT may likewise damage the cochlear nerve in the narrow bone canal (26). Human temporal bone studies uncovered that patients who received cisplatin, RT, or both, ended up with a decrement of spiral ganglion cells alongside the loss of internal and external hair cells and atrophy of stria vascularis (27).

RI-SNHL can have sudden or progressive character. Sudden SNHL (SSNHL) can be defined as SNHL of at least $30 \mathrm{~dB}$ in three consecutive frequencies occurring over three days or less (28), while progressive SNHL is described as a hearing loss $\geq 30 \mathrm{~dB}$ which shows $\geq 10 \mathrm{~dB}$ regression at any frequencies during the consecutive 3-monthly audiometric follow-ups (29). Severe SNHL described as $\geq 20 \mathrm{~dB}$ difference between the irradiated and unirradiated ears by some authors (30,31); while some others accept $\geq 10-15 \mathrm{~dB}$ loss as the critical cut-off for severe loss (32,33). Though the clinical stage may settle in 2 years for permanent SNHL $(>15 \mathrm{~dB})$, yet, this interval may lengthen to 3 to 4 years for more severe (>30dB) SNHL (34). Nevertheless, in studies with longer follow-up periods, such as 13 years or more, SNHL is specified to have a stable characteristic rather than being progressive (35).

\section{Scoring Systems for Hearing Loss}

Ototoxicity is a complication induced by antibiotics, diuretics, chemotherapeutics, and RT; which diminishes hearing function and quality of daily life measures as a result of damaged hearing structures including the vestibular, cochlear or conductive bony structures $(36,37)$. Regarding the RT-induced SNHL, 
usually, the insult first affects the cells responsible for the high-frequency hearing $(\geq 4 \mathrm{kHz})$ at basal segments of the cochlea and then propagates to the cells responsible for the low-frequency hearing $(<4 \mathrm{kHz})$ at the apical region. While the loss in the speech range frequencies $(<4 \mathrm{kHz})$ prompts troubles in understanding the daily public conversations, typical high frequency losses $(\geq 4 \mathrm{kHz})$ cause impaired recognition and differentiation of sounds at higher frequencies, including the natural sounds such as bird crowing or bee buzzing, and sounds of musical instruments. Since the hearing function is critical for social relations, communication, education, work-life, and expression of feelings the detection and grading of objective hearing loss is mandatory for the timely interventions and healthy maintenance of a qualified lifestyle. Therefore, objective audiometric evaluations before and during the RT or CCRT, maintenance chemotherapy, and follow-up periods is essential. Although the recommended frequency range for hearing evaluations involves the frequencies between $0.25-8.0 \mathrm{kHz}$, explicit considerations may be required in some adult risk groups and pediatric patients.

The most frequently used hearing loss scoring systems are as depicted in Tables 1 to 5 .

Table 1. CTCAEv4 and ASHA scoring criteria

\begin{tabular}{|c|c|}
\hline \multirow[t]{6}{*}{ CTCAEv4 (adult) } & Audiograms evaluated at $1,2,3,4,6$ and $8 \mathrm{kHz}$ \\
\hline & Grade 0: No hearing loss. \\
\hline & $\begin{array}{l}\text { Grade 1: } 15-25 \mathrm{~dB} \text { threshold shift on two consequent frequencies or } \\
\text { subjective alteration while no Grade } 1 \text { threshold shift is present in at } \\
\text { least one ear }\end{array}$ \\
\hline & $\begin{array}{l}\text { Grade 2: }>25 \mathrm{~dB} \text { threshold shift on two consequent frequencies in at } \\
\text { least one ear }\end{array}$ \\
\hline & $\begin{array}{l}\text { Grade 3: }>25 \mathrm{~dB} \text { threshold shift on three consequent frequencies in at } \\
\text { least one ear }\end{array}$ \\
\hline & Grade 4: Severe bilateral hearing loss ( $\geq 80 \mathrm{~dB}$ at $2 \mathrm{kHz})$ \\
\hline \multirow[t]{2}{*}{ ASHA } & No: No hearing loss. \\
\hline & $\begin{array}{l}\text { Yes: } \geq 20 \mathrm{~dB} \text { threshold shift at any frequency rate or } \geq 10 \mathrm{~dB} \text { threshold } \\
\text { shift on two consequent frequencies }\end{array}$ \\
\hline
\end{tabular}

CTCAEv4, Common Terminology Criteria for Adverse Events version 4; ASHA, American Speech-

Language-Hearing Association

Table 2. Chang and Brock scoring criteria

\begin{tabular}{|l|l|c|l|}
\hline $\begin{array}{l}\text { Chang } \\
\text { Score }\end{array}$ & $\begin{array}{l}\text { Threshold of hearing loss } \\
(\mathrm{dB})\end{array}$ & Brock Score & $\begin{array}{l}\text { Threshold of hearing loss } \\
(\mathrm{dB})\end{array}$ \\
\hline 0 & $\leq 20 \mathrm{~dB}$ at 1,2 and $4 \mathrm{kHz}$ & $\mathbf{0}$ & $<40 \mathrm{~dB}$ at all frequencies \\
\hline $1 \mathrm{a}$ & $\geq 40 \mathrm{~dB}$ in between 6-12 & $\mathbf{1}$ & $>40 \mathrm{~dB}$ at $8 \mathrm{kHz}$ \\
$1 \mathrm{~b}$ & $\begin{array}{l}\mathrm{kHz} \\
>20 \text { and }<40 \mathrm{~dB} \text { at } 4 \mathrm{kHz}\end{array}$ & & \\
\hline $\begin{array}{l}2 \mathrm{a} \\
2 \mathrm{~b}\end{array}$ & $\geq 40 \mathrm{~dB}$ at $\geq 4 \mathrm{kHz}$ & $\mathbf{2}$ & $\geq 40 \mathrm{~dB}$ at $\geq 4 \mathrm{kHz}$ \\
\hline 3 & $\geq 20$ and $<40 \mathrm{~dB}$ at $<4 \mathrm{kHz}$ & & \\
\hline 4 & $\geq 40 \mathrm{~dB}$ at $\geq 2 \mathrm{kHz}$ & $\mathbf{3}$ & $\geq 40 \mathrm{~dB}$ at $\geq 2 \mathrm{kHz}$ \\
\hline
\end{tabular}

Table 3. Toxicity criteria according to the Radiation Therapy Oncology Group scoring system

\begin{tabular}{|c|l|}
\hline Grade & Toxicity \\
\hline 0 & No difference from the beginning \\
\hline 1 & $\begin{array}{l}\text { Mild external otitis with erythema, pruritus, secondary to dry desquamation not } \\
\text { requiring medication. Audiogram unchanged from baseline }\end{array}$ \\
\hline 2 & $\begin{array}{l}\text { Moderate external otitis requiring topical medication/serous otitis media/hypoacusis } \\
\text { on testing only }\end{array}$ \\
\hline
\end{tabular}




\begin{tabular}{|c|l|}
\hline 3 & $\begin{array}{l}\text { Severe external otitis with discharge or moist desquamation/symptomatic } \\
\text { hypoacusis/tinnitus, not drug related }\end{array}$ \\
\hline 4 & Deafness \\
\hline
\end{tabular}

Table 4. Late stage ear toxicity according to LENT/SOMA score

\begin{tabular}{|c|c|c|c|c|}
\hline & Grade 1 & Grade 2 & Grade 3 & Grade 4 \\
\hline $\begin{array}{l}\text { Subjective } \\
\text { Pain } \\
\text { Tinnitus } \\
\text { Hearing }\end{array}$ & $\begin{array}{l}\text { Seldom } \\
\text { Seldom } \\
\text { Minimal loss, no } \\
\text { difference in } \\
\text { daily basis }\end{array}$ & $\begin{array}{l}\text { Sometimes, } \\
\text { tolerable } \\
\text { Sometimes } \\
\text { Difficulty of } \\
\text { understanding } \\
\text { low-volume } \\
\text { conversations }\end{array}$ & $\begin{array}{l}\text { Severe } \\
\text { Persistent } \\
\text { Difficulty of } \\
\text { understanding } \\
\text { high-volume } \\
\text { conversations }\end{array}$ & $\begin{array}{l}\text { Intolerable } \\
\text { Persistent } \\
\text { Complete } \\
\text { deafness }\end{array}$ \\
\hline $\begin{array}{l}\text { Objective } \\
\text { Skin } \\
\text { Hearing }\end{array}$ & $\begin{array}{l}\text { Dry } \\
\text { desquamation } \\
<10 \mathrm{~dB} \text { loss at } \\
\geq 1 \text { frequencies }\end{array}$ & $\begin{array}{l}\text { External otitis } \\
10-15 \mathrm{~dB} \text { loss } \geq 1 \\
\text { frequencies }\end{array}$ & $\begin{array}{l}\text { Superficial ulcer } \\
15-20 \mathrm{~dB} \text { loss } \\
\text { at } \geq 1 \text { frequencies }\end{array}$ & $\begin{array}{l}\text { Necrosis } \\
>20 \mathrm{~dB} \text { loss at } \\
\geq 1 \\
\text { frequencies }\end{array}$ \\
\hline $\begin{array}{l}\text { Management } \\
\text { Pain } \\
\text { Skin } \\
\text { Hearing } \\
\text { Loss }\end{array}$ & $\begin{array}{l}\text { Non-narcotic } \\
\text { medication } \\
\text { Lubricant }\end{array}$ & $\begin{array}{l}\text { Non-narcotic } \\
\text { medication } \\
\text { Drop-antibiotic }\end{array}$ & $\begin{array}{l}\text { Narcotic } \\
\text { medication } \\
\text { Tympanic } \\
\text { membrane } \\
\text { Hearing aid }\end{array}$ & $\begin{array}{l}\text { Intravenous } \\
\text { narcotics } \\
\text { Surgery }\end{array}$ \\
\hline
\end{tabular}

Abbreviation: LENT/SOMA, Late Effects of Normal Tissue/Somatic Objective Management Analytic

Table 5. Gardner Robertson Hearing Classification

\begin{tabular}{|l|l|c|c|}
\hline Grade & Hearing Level & $\begin{array}{l}\text { Pure tone average } \\
(\mathrm{dB})\end{array}$ & $\begin{array}{l}\text { Speech discrimination score } \\
(\%)\end{array}$ \\
\hline I & $\begin{array}{l}\text { Good to } \\
\text { excellent }\end{array}$ & $0-30$ & \multicolumn{2}{|c|}{} \\
\hline II & Serviceable & $31-50$ & $50-69$ \\
\hline III & $\begin{array}{l}\text { Non- } \\
\text { serviceable }\end{array}$ & $51-90$ & $5-49$ \\
\hline IV & Poor & $91-$ maximum & $1-4$ \\
\hline V & None/deaf & Non-testable & 0 \\
\hline
\end{tabular}

Albeit each scoring system provides valuable objective information about the hearing status, yet each system has its pros and cons compared to other systems as described below. For example; the Common Terminology Criteria for Adverse Events Version-4 (CTCAEv4) and American Speech-Language-Hearing Association (ASHA) (Table 1) are lacking to assess hearing loss at ultra-high frequencies. In this regard, CTCAEv4 is particularly noted to insufficiently report the degree of hearing loss and its clinical importance in pediatric patients. Though the RT-induced hearing loss initially occurs at ultra-high frequencies, CTCAEv4 ignores these frequencies due to its assessment rate restricted to the frequencies between 1 to 8.0 $\mathrm{kHz}$. So also, gradual increments in hearing loss cannot be evaluated with ASHA scoring system as the frequency range of hearing loss is not specified. Even though the RI-SNHL is chronic type ototoxicity, the Radiation Therapy Oncology Group (RTOG) criteria likewise don't assess chronic ototoxicity and preferably 
used for evaluation of acute ototoxic events for retrospective investigations (Table 3). The Late Effects of Normal Tissue/Somatic Objective Management Analytic (LENT-SOMA) criteria (Table 4) provides a prospective evaluation of late-stage toxicity. However, LENT-SOMA is primarily used for chemotherapy studies and is noted to be insufficient in the assessment of quantitatively small but clinically significant changes, and as a noteworthy disadvantage, it does not clarify the mainly affected compartment(s) of the cochlea (38). The classification proposed by Gardner and Robertson is another commonly used classification system, but again this system has the disadvantage of being useful in assessment of hearing preservation after surgery or SRS (39).

Further complicating the situation, wide variability between the affected patients populations' regarding the patient age, total and per fraction dose of RT, RT technique, concurrent use of ototoxic antibiotics or chemotherapeutics, and scoring methodologies render it difficult to compare different studies evaluating the RT-induced ototoxicity. Thus, more objective scoring systems determining the affected compartment of the hearing apparatus and evaluating the severity of acute and chronic ototoxic events in pediatric and adult cancer populations are urgently required.

\section{Risk Factors for RI-SNHL}

The frequently referred risk factors for RT- or CRT-induced SNHL are summarized in Table 6.

Table 6. Risk Factors for Post-RT SNHL Development

\begin{tabular}{|l|l|l|}
\hline Treatment related factors & \multicolumn{1}{|c|}{ Patient related factors } & \multicolumn{1}{|c|}{ Tumor related factors } \\
\hline High total RT dose & Advanced age & Unfavorable tumor \\
High marginal dose* & Neurofibromatosis type-2 & localization \\
Cisplatin & Diminished basal hearing & (Nasopharynx, skull \\
SRS versus FSRT & Male gender & base, etc.) \\
Conventional RT (versus & Post-RT serous otitis & Large tumor size \\
IMRT) & Hypersensitivity to RT or & High-location lymph \\
High dose-rate & cisplatin & nodes \\
Fraction dose $>2$ Gy & & Cystic or solid type \\
Furosemide & & tumour \\
Aminoglycosides & & \\
\hline
\end{tabular}

*For stereotactic radiosurgery

Abbreviations: RT: Radiotherapy; SRS: Stereotactic radiosurgery; FSRT: Fractionated stereotactic radiotherapy; IMRT: Intensity-Modulated radiotherapy

In general, the impact of patient's age on SNHL development is debated. Albeit many researchers proposed the geriatric age as a risk factor (40-42), Zuur et al. proposed that the magnitude of hearing loss was significantly higher in younger patients than their older counterparts (43). In this manner, young patients with good basal hearing levels will experience more severe hearing loss after RT or CRT which will lead to lower hearing threshold levels years after the completion of treatment. But, suggesting a radiation hypersensitivity of the cochlea, presence of age-related degenerative cochlear changes in elderly patients were also proposed as a worsening factor SNHL actuated by RT or CRT (44).

To our best information, presently the most grounded risk factors for RT-induced SNHL are total and per fraction RT doses exposed by the cochlea. Moreover, it has been reported that the RI-SNHL incidence and severity were exhibiting gradual increments paralleling with the total RT dose, particularly with cochlear doses beyond $45 \mathrm{~Gy}$ (45-48). The outcomes of the large retrospective analysis incorporating 325 head-neck cancer patients reported by Bhandare et al. clearly demonstrated that the total cochlear RT dose was independently associated with increased 5-year SNHL risk in multivariate analysis $(3 \%$ with $\leq 60,5$ Gy versus $37 \%$ with $60,5 \mathrm{~Gy} ;>\mathrm{p}<0.0001$ ) (48). Although the radiation dose limits for cochlea is usually set at $<45 \mathrm{~Gy}$, yet, various investigators recommend $<35-40 \mathrm{~Gy}$ and $<30 \mathrm{~Gy}$ for adult $(49,50)$ and pediatric patients (51), respectively, while others set the critical threshold at $\geq 47-55$ Gy $(50,53,58,59)$. Differing significantly from these traditional dose limits Hermann et al proposed the 20-25 Gy range as the significant cut off for $\geq 15 \mathrm{~dB}$ change in hearing thresholds in $50 \%$ of the irradiated patients (52). 
The influence of fractionation (conventional versus hyper-fractionation) is debated for the conventional dose per fraction range of 1.2 to 2 Gy (48). In some vestibular schwannoma studies, it was noticed that the hearing function was more effectively spared with fractionated SRS than the single-dose SRS protocols $(53,54)$. However, regarding the 8-year hearing preservation rates, Meijer et al. found no statistically significant difference between single- and multi-fractionated SRS schemes in 129 vestibular schwannoma patients treated with one of the $5 \times 5 \mathrm{~Gy}, 5 \times 4 \mathrm{~Gy}, 1 \times 10 \mathrm{~Gy}$, or $1 \times 12.5 \mathrm{~Gy}$ SRS conventions (55). To date, no exact latency interval has been proposed for post-RT SNHL development, yet accessible proof recommends that compared to single-fraction SRS regimes, fractionated SRS may extend the latency interval from median 4 months to $18-24$ months $(38,44)$.

It is well-perceived that the concurrent use of chemotherapy with RT, particularly the cisplatin enhances the locoregional disease control and survival outcomes in many tumor sites including the head and neck $(56,57)$. Cisplatin, as a strong cytotoxic and radio-sensitizing agent, targets the cellular DNA via the production of reactive oxygen radicals and triggering of the apoptotic pathways, which are also common for RT-induced cell killing $(58,59)$. On animal researches, the ototoxic effects of both radiation and cisplatin are shown by targeting similar structures of the cochlea (external and internal hair cells, stria vascularis and nerve ends) $(60,61)$. Various studies demonstrated that the cisplatin per cycle doses of $\geq 50 \mathrm{mg} / \mathrm{m}^{2}$ or cumulative doses $\geq 400 \mathrm{mg} / \mathrm{m}^{2}$ was associated with approximately 33\% SNHL development (42,43,62-64). Hitchock et al. constructed a model to predict dose-dependent hearing loss for RT or cisplatin-based chemotherapy either alone or in combination. For patients only receiving RT, no significant hearing loss was found at doses to the cochlea of $<40$ Gy. Patients receiving $100 \mathrm{mg} / \mathrm{m}^{2}$ or $40 \mathrm{mg} / \mathrm{m}^{2}$ of cisplatin chemotherapy had an estimated $+21.5 \mathrm{~dB}$ and $+9.5 \mathrm{~dB}$ hearing loss at $8.0 \mathrm{kHz}$ with low radiation doses $(10 \mathrm{~Gy})$, which rose to $+38.4 \mathrm{~dB}$ and $+18.9 \mathrm{~dB}$ for high radiation doses (40 Gy). In contrast, patients who received <40 Gy cochlear dose and no chemotherapy did not experience any notable hearing loss (58). In a seminal investigation, Rademaker et. al evaluated the auditory toxicity associated with dose- and schedule- intensive cisplatin/gemcitabine chemotherapy in non-small-cell lung carcinoma patients and demonstrated that hearing loss after cisplatin therapy occurred mainly at high frequencies and at cisplatin dosages over 60 $\mathrm{mg} / \mathrm{m}^{2}$, which was more pronounced when cisplatin was given once every 2 weeks (64). Theunissen et al. compared the SNHL incidences after RT versus CRT in a systematic review comprising 21 studies (1). Although the wide range of SNHL incidence rates made it impossible to draw any conclusions on the severity of RT- and CRT-induced ototoxicity, yet, the authors reported that the incidence rates of meaningful SNHL after RT and CRT were $0 \%$ to $43 \%$ versus $17 \%$ to $88 \%$, respectively. In this review, the adverse factors that influenced the risk of SNHL were identified as the higher RT dose to the cochlea, longer follow-up time, advanced patient age, diminished baseline hearing level, and higher cisplatin dose.

Considering the aforementioned facts, it is imperative to determine pre-treatment hearing condition and risk factors to determine the true incidence of SNHL in patients undergoing RT or CRT. Supporting this notion, it has been repeatedly emphasized that $>50 \%$ of all nasopharyngeal cancer patients present with conduction type hearing loss secondary to serous otitis media (65-67). It should be remembered that the toxic effects of cisplatin may progressively continue for years even when used as a single agent without RT $(68,69)$. To affirm, when compared to the cisplatin naive population, serum cisplatin levels were 30 times higher in the patients' cohort treated with cisplatin after 8 to 75 months of its administration (70). Moreover, another study demonstrated that cisplatin was detectable in the plasma even after 20 years of its utilization (71).

\section{Prevention and Treatment of Sensorial Neural Hearing Loss}

The cumulative ototoxicity risk of concurrent use of RT and cisplatin is without no doubt much higher than the risk of either treatment alone. Further complicating the problem, a recent study by Clemens et al. showed that the meaningful hearing loss rates were $45 \%$ in cisplatin-, $17 \%$ in carboplatin-treated, and $75 \%$ in childhood cancer survivors ( $\mathrm{N}=451)$ who received both agents (72), and the risk was increased by a factor of 2.3 when patients were co-treated with furosemide in absence of RT.

Since cisplatin is the indispensable component of many anticancer treatment protocols, many preclinical investigations have been performed to develop agents exerting otoprotective actions against cisplatin. But, unfortunately, just a couple of them could move into clinical studies. Studies of amifostine's protective effect against cisplatin-induced ototoxicity in children with hepatoblastoma and germ cell tumors failed to show otoprotection $(73,74)$. Nevertheless, the trial reported by Fouladi et al. in 97 average-risk medulloblastomas revealed that the amifostine use was associated with a significantly reduced requirement for hearing aid in at 
least one ear because of grade 3 ototoxicity (14.5\% versus $37.1 \% ; \mathrm{P}=0.005)$ at 1 -year of treatment (75), which was recently confirmed by a retrospective analysis (76). Sodium thiosulfate is another antioxidant tested for its otoprotective actions. Preclinical studies and initial phase 1-2 trials indicated that sodium thiosulfate has a potential otoprotective effect, with most extreme viability occurring particularly when administered 4 to 8 hours after cisplatin (77-80). Considering the tumor protective actions, further pharmacokinetic evidence demonstrated the 6 hours interval as the safe timing for the delayed administration of sodium thiosulfate $(81,82)$. The SIOPEL-6 was a phase 3 trial designed to investigate whether delayed sodium thiosulfate administration would reduce the incidence and severity of the cisplatininduced hearing loss. The authors randomized 109 children who had standard-risk hepatoblastoma to one of cisplatin alone or cisplatin plus sodium thiosulfate arms (83). The primary endpoint was the absolute hearing threshold measured by pure-tone audiometry. The incidence of SNHL of grade $\geq 1$ was significantly lower in the cisplatin-sodium thiosulfate group as compared to its cisplatin-alone counterpart (33\% versus $63 \%$; $\mathrm{P}=0.002$ ), indicating a $48 \%$ lower incidence of hearing loss with delayed sodium thiosulfate administration with no negative impact on the survival outcomes (83). N-acetylcysteine, a precursor to the antioxidant glutathione with strong free radical scavenging actions, is one of the few agents proposed to exhibit otoprotection against cisplatin-induced ototoxic actions $(84,85)$. In an in vitro study, Feghali et al. demonstrated a dose-dependent otoprotective effect of $\mathrm{N}$-acetylcysteine against cisplatin on both auditory neurons and hair cells (86). Sarafraz et al conducted a double-blind randomized trial to compare the otoprotective impact of transtympanic injections of $\mathrm{N}$-acetylcysteine and dexamethasone in 60 cisplatintreated patients (87). Hearing acuity was evaluated with pure tone audiometry. Altogether, 114 transtympanic infusions were performed (57 in each group). The authors reported that no significant changes in auditory thresholds were recorded in the ears treated with $\mathrm{N}$-acetylcysteine, dexamethasone-treated patients exhibited a significant decrease of auditory thresholds at the $8.0 \mathrm{kHz}$ frequency band $(\mathrm{P}=0.001)$. Albeit additional proof is required, based on the accessible favorable data, both the sodium thiosulfate and $\mathrm{N}$-acetylcysteine have received a Food and Drug Administration orphan status for the indication of otoprotection (88).

Although many agents have been tested for their otoprotective functions, to our best information, no protective measure gained evidence-based acceptance to date. Therefore, radiation-initiated SNHL ought to be treated as idiopathic SSNHL with supportive measures such as steroid administration and hyperbaric oxygen therapy, hearing aid usage, or cochlear implantation in appropriately selected cases. In this context, it is imperative to spare cochlea by using more sophisticated RT techniques, such as the intensity-modulated $\mathrm{RT}$, and obey the proposed dose restrictions for cochlea. In brief, as the best effort, the cochlear dose ought to be kept $\leq 40-45$ Gy for conventionally fractionated RT and $<10$ Gy for concurrently administered RT plus cisplatin regimens. For SRS, the cochlear dose should not exceed 10-12 Gy to minimize the risk for hearing loss.

\section{Conclusion}

RI-SNHL is usually a late-onset progressive and irreversible treatment complication which may involve one or both ears relying upon the treatment methodology chosen. As a rule, RI-SNHL initially affects the high frequencies which may spread to lower frequencies. At present, in spite of the fact that amiphostine, Nacetylcysteine, and sodium thiosulphate exhibited some viability in prevention of cisplatin-induced SNHL, yet the proof isn't sufficiently robust to suggest their utilization as an otoprotector for patients experiencing RT or CRT. Thusly, in absence of effective medications with strong otoprotective or treatment functions, the best otoprotective measure is the utilization of IMRT with obeying the recommended cochlear dose constraints together with avoidance of ototoxic drugs, such as aminoglycoside antibiotics. We recommended $\leq 40-45$ Gy and <10 Gy cochlear doses for conventionally fractionated RT alone and concurrently administered RT plus cisplatin regimens. In like manner, the cochlear dose should not exceed 10-12 Gy to minimize the hazard for hearing loss after SRS. Future effort should focus on the identification of at-risk individuals and development of highly selective and efficient otoprotectors with no tumor promoting actions. 


\author{
Declarations \\ Disclosure: The author reports no conflicts of interest in this work \\ Founding source: None to declare \\ Acknowledgements: Not applicable \\ Author Contribution: All authors contributed equally
}

\title{
References
}

[1] Theunissen EA, Bosma SC, Zuur CL, et al. Sensorineural hearing loss in patients with head and neck cancer after chemoradiotherapy and radiotherapy: A systematic review of the literature. Head Neck 2015;37:281-92.

[2] Song S, Lambert PF. Different responses of epidermal and hair follicular cells to radiation correlate with distinct patterns of p53 and p21 induction. Am J Pathol 1999;155:1121-7.

[3] Low WK, Tan MG, Sun L, et al. Dose-dependant radiation-induced apoptosis in a cochlear cell-line. Apoptosis 2006;11:2127-36.

[4] Offer H, Erez N, Zurer I, et al. The onset of p53-dependent DNA repair or apoptosis is determined by the level of accumulated damaged DNA. Carcinogenesis 2002;23:1025-32.

[5] Mikkelsen RB, Wardman P. Biological chemistry of reactive oxygen and nitrogen and radiationinduced signal transduction mechanisms. Oncogene. 2003;22(37):5734-54.

[6] Ward JF. The complexity of DNA damage: relevance to biological consequences. Int J Radiat Biol. 1994;66(5):427-32.

[7] Azzam EI, Jay-Gerin JP, Pain D. Ionizing radiation-induced metabolic oxidative stress and prolonged cell injury. Cancer Lett. 2012;327(1-2):48-60.

[8] Low WK, Tan MG, Sun L, et al. Dose-dependent radiation-induced apoptosis in a cochlear cell-line. Apoptosis. 2006;11(12):2127-36.

[9] Chao C, Saito S, Kang J, et al. p53 transcriptional activity is essential for p53-dependent apoptosis following DNA damage.EMBO J. 2000;19(18):4967-75.

[10] Nagasawa H, Cremesti A, Kolesnick R, Fuks Z, Little JB. Involvement of membrane signaling in the bystander effect in irradiated cells. Cancer Res. 2002;62(9):2531-4.

[11] Girden E, Culler E. Auditory effects of roentgen rays in dogs. Am J Roentg 1933;30:215-20.

[12] Kozlov MI. Changes in the peripheral section of the auditory analysor in acute radiation sickness. Vestn Otorinolaringol. 1958;20(2):29-35.

[13] Dale RG. The use of small fraction numbers in high dose-rate gynaecological afterloading: some radiobiological considerations. Br J Radiol. 1990;63(748):290-4.

[14] Miller MW, Riedel G, Hoistad D, et al. Ototoxicity after combined platinum and fractionated radiation in a novel guinea pig model. Am J Otolaryngol. 2009;30(1):1-7.

[15] Lewis MJ, DuBois SG, Fligor B, et al. Ototoxicity in children treated for osteosarcoma. Pediatr Blood Cancer. 2009;52:387-391.

[16] Nitz A, Kontopantelis E, Bielack S, et al. Prospective evaluation of cisplatin- and carboplatinmediated ototoxicity in paediatric and adult soft tissue and osteosarcoma patients. Oncol Lett. 2013;5:311-315.

[17] Schell MJ, McHaney VA, Green AA, et al. Hearing loss in children and young adults receiving cisplatin with or without prior cranial irradiation. J Clin Oncol. 1989;7:754-760.

[18] Bhandare N, Jackson A, Eisbruch A, et al. Radiation therapy and hearing loss. Int J Radiat Oncol Biol Phys. 2010;76(3 Suppl):S50-7.

[19] Ho WK, Wei WI, Kwong DL, et al. Long-term sensorineural hearing deficit following radiotherapy in patients suffering from nasopharyngeal carcinoma: A prospective study. Head Neck 1999;21:54753.

[20] Chang SD, Poen J, Hancock SL, et al. Acute hearing loss following fractionated stereotactic radiosurgery for acoustic neuroma. Report of two cases. J Neurosurg 1998;89:321-5.

[21] Yamane H, Nakai Y, Takayama M, et al. Appearance of free radicals in the guinea pig inner ear after noise-induced acoustic trauma. Eur Arch Otorhinolaryngol 1995;252:504-8.

[22] Gamble JE, Peterson EA, Chandler JR. Radiation effects on the inner ear. Arch Otolaryngol. 1968;88(2):156-61. 
[23] Winther FO. X-ray irradiation of the inner ear of the guinea pig. Early degenerative changes in the vestibular sensory epithelia. Acta Otolaryngol. 1969;68(6):514-25.

[24] Bohne BA, Marks JE, Glasgow GP. Delayed effects of ionizing radiation on the ear. Laryngoscope. 1985;95(7 Pt 1):818-28.

[25] Yang X, Lu Y, Chen Z. Delayed damage of ionizing radiation on the inner ear. Zhonghua Er Bi Yan Hou Ke Za Zhi. 1997;32(4):222-5.

[26] Sakamoto T, Shirato H, Takeichi N, et al. Medication for hearing loss after fractionated stereotactic radiotherapy (SRT) for vestibular schwannoma. Int J Radiat Oncol Biol Phys. 2001;50(5):1295-8.

[27] Hoistad DL, Ondrey FG, Mutlu C, et al. Histopathology of human temporal bone after cis-platinum, radiation, or both. Otolaryngol Head Neck Surg. 1998;118(6):825-32.

[28] Wilson WR, Byl FM, Laird N. The efficacy of steroids in the treatment of idiopathic sudden hearing loss. A double-blind clinical study. Arch Otolaryngol. 1980;106(12):772-6.

[29] Bloch DB, San Martin JE, Rauch SD, Moscicki RA, Bloch KJ. Serum antibodies to heat shock protein 70 in sensorineural hearing loss. Arch Otolaryngol Head Neck Surg. 1995;121(10):1167-71.

[30] Anteunis LJ, Wanders SL, Hendriks JJ, et al. A prospective longitudinal study on radiation-induced hearing loss. Am J Surg. 1994;168(5):408-11.

[31] Chen WC, Liao CT, Tsai HC, et al. Radiation-induced hearing impairment in patients treated for malignant parotid tumor. Ann Otol Rhinol Laryngol. 1999;108(12):1159-64.

[32] Honoré HB, Bentzen SM, Møller K, Grau C. Sensori-neural hearing loss after radiotherapy for nasopharyngeal carcinoma: individualized risk estimation. Radiother Oncol. 2002;65(1):9-16.

[33] Raaijmakers E, Engelen AM. Is sensorineural hearing loss a possible side effect of nasopharyngeal and parotid irradiation? A systematic review of the literature. Radiother Oncol. 2002;65(1):1-7.

[34] Grau C, Overgaard J. Postirradiation sensorineural hearing loss: A common but ignored late radiation complication. Int J Radiat Oncol Biol Phys 1996;36:515-7.

[35] Johannesen TB, Rasmussen K, Winther FO, et al. Late radiation effects on hearing, vestibular function, and taste in brain tumor patients. Int J Radiat Oncol Biol Phys 2002;53:86-90.

[36] Miaskowski C, Mastick J, Paul SM, et al. Impact of chemotherapy-induced neurotoxicities on adult cancer survivors' symptom burden and quality of life. J Cancer Surviv. 2018;12(2):234-245.

[37] Weiss A, Sommer G, Schindera C, et al. Hearing loss and quality of life in survivors of paediatric CNS tumours and other cancers. Qual Life Res. 2019;28(2):515-21.

[38] Jereczek-Fossa BA, Zarowski A, Milani F, Orecchia R. Radiotherapy-induced ear toxicity. Cancer Treat Rev. 2003;29(5):417-30.

[39] Gardner G, Robertson JH. Hearing preservation in unilateral acoustic neuroma surgery. Ann Otol Rhinol Laryngol. 1988;97(1):55-66.

[40] Zuur CL, Simis YJ, Lamers EA, et al. Risk factors for hearing loss in patients treated with intensitymodulated radiotherapy for head-and-neck tumors. Int J Radiat Oncol Biol Phys 2009;74:490-6.

[41] Herrmann F, Dorr W, Muller R, et al. A prospective study on radiation-induced changes in hearing function. Int J Radiat Oncol Biol Phys 2006;65:1338-44.

[42] Chan SH, Ng WT, Kam KL, et al. Sensorineural hearing loss after treatment of nasopharyngeal carcinoma: A longitudinal analysis. Int J Radiat Oncol Biol Phys 2009;73:1335-42.

[43] Zuur CL, Simis YJ, Lansdaal PE, et al. Ototoxicity in a randomized phase iii trial of intra-arterial compared with intravenous cisplatin chemoradiation in patients with locally advanced head and neck cancer. J Clin Oncol 2007;25:3759-65.

[44] Ho WK, Wei WI, Kwong DL, et al. Long-term sensorineural hearing deficit following radiotherapy in patients suffering from nasopharyngeal carcinoma: A prospective study. Head Neck 1999;21:54753.

[45] Pan CC, Eisbruch A, Lee JS, et al. Prospective study of inner ear radiation dose and hearing loss in head-and-neck cancer patients. Int J Radiat Oncol Biol Phys 2005;61:1393-402.

[46] van der Putten L, de Bree R, Plukker JT, et al. Permanent unilateral hearing loss after radiotherapy for parotid gland tumors. Head Neck 2006;28:902-8.

[47] Grau C, Moller K, Overgaard M, et al. Sensori-neural hearing loss in patients treated with irradiation for nasopharyngeal carcinoma. Int J Radiat Oncol Biol Phys 1991;21:723-8.

[48] Bhandare N, Antonelli PJ, Morris CG, et al. Ototoxicity after radiotherapy for head and neck tumors. Int J Radiat Oncol Biol Phys 2007;67:469-79. 
[49] Bhide SA, Harrington KJ, Nutting CM. Otological toxicity after postoperative radiotherapy for parotid tumours. Clin Oncol (R Coll Radiol) 2007;19:77-82.

[50] Fleury B, Lapeyre M. [tolerance of normal tissues to radiation therapy: Ear]. Cancer Radiother 2010;14:284-9.

[51] Grewal S, Merchant T, Reymond R, et al. Auditory late effects of childhood cancer therapy: A report from the children's oncology group. Pediatrics 2010;125:e938-50.

[52] Herrmann F, Dorr W, Muller R, et al. A prospective study on radiation-induced changes in hearing function. Int J Radiat Oncol Biol Phys 2006;65:1338-44.

[53] Combs SE, Volk S, Schulz-Ertner D, et al. Management of acoustic neuromas with fractionated stereotactic radiotherapy (fsrt): Long-term results in 106 patients treated in a single institution. Int $\mathbf{J}$ Radiat Oncol Biol Phys 2005;63:75-81.

[54] Andrews DW, Suarez O, Goldman HW, et al. Stereotactic radiosurgery and fractionated stereotactic radiotherapy for the treatment of acoustic schwannomas: Comparative observations of 125 patients treated at one institution. Int J Radiat Oncol Biol Phys 2001;50:1265-78.

[55] Meijer OW, Vandertop WP, Baayen JC, et al. Single-fraction vs. Fractionated linac-based stereotactic radiosurgery for vestibular schwannoma: A single-institution study. Int J Radiat Oncol Biol Phys 2003;56:1390-6.

[56] Pignon JP, Bourhis J, Domenge C, et al. Chemotherapy added to locoregional treatment for head and neck squamous-cell carcinoma: Three meta-analyses of updated individual data. MACH-NC collaborative group. Meta-analysis of chemotherapy on head and neck cancer. Lancet 2000;355:949-55.

[57] Pignon JP, le Maitre A, Maillard E, et al. Meta-analysis of chemotherapy in head and neck cancer (MACH-NC): An update on 93 randomised trials and 17,346 patients. Radiother Oncol 2009;92:414.

[58] Hitchcock YJ, Tward JD, Szabo A, et al. Relative contributions of radiation and cisplatin-based chemotherapy to sensorineural hearing loss in head-and-neck cancer patients. Int J Radiat Oncol Biol Phys 2009;73:779-88.

[59] Low WK, Kong SW, Tan MG. Ototoxicity from combined cisplatin and radiation treatment: An in vitro study. Int J Otolaryngol 2010;2010:523976.

[60] Gamble JE, Peterson EA, Chandler JR. Radiation effects on the inner ear. Arch Otolaryngol 1968;88:156-61.

[61] Winther FO. X-ray irradiation of the inner ear of the guinea pig. Early degenerative changes in the vestibular sensory epithelia. Acta Otolaryngol 1969;68:514-25.

[62] Chen WC, Jackson A, Budnick AS, et al. Sensorineural hearing loss in combined modality treatment of nasopharyngeal carcinoma. Cancer 2006;106:820-9.

[63] Pearson SE, Meyer AC, Adams GL, et al. Decreased hearing after combined modality therapy for head and neck cancer. Am J Otolaryngol 2006;27:76-80.

[64] Rademaker-Lakhai JM, Crul M, Zuur L, et al. Relationship between cisplatin administration and the development of ototoxicity. J Clin Oncol 2006;24:918-24.

[65] Balm AJ, Plaat BE, Hart AA, et al. [nasopharyngeal carcinoma: Epidemiology and treatment outcome]. Ned Tijdschr Geneeskd 1997;141:2346-50.

[66] Kew J, King AD, Leung SF, et al. Middle ear effusions after radiotherapy: Correlation with preradiotherapy nasopharyngeal tumor patterns. Am J Otol 2000;21:782-5.

[67] Morton RP, Woollons AC, McIvor NP. Nasopharyngeal carcinoma and middle ear effusion: Natural history and the effect of ventilation tubes. Clin Otolaryngol Allied Sci 1994;19:529-31.

[68] Bertolini P, Lassalle M, Mercier G, et al. Platinum compound-related ototoxicity in children: Longterm follow-up reveals continuous worsening of hearing loss. J Pediatr Hematol Oncol 2004;26:64955.

[69] Sprauten M, Darrah TH, Peterson DR, et al. Impact of long-term serum platinum concentrations on neuro- and ototoxicity in cisplatin-treated survivors of testicular cancer. J Clin Oncol 2012;30:3007.

[70] Brouwers EE, Huitema AD, Beijnen JH, et al. Long-term platinum retention after treatment with cisplatin and oxaliplatin. BMC Clin Pharmacol 2008;8:7. 
[71] Gietema JA, Meinardi MT, Messerschmidt J, et al. Circulating plasma platinum more than 10 years after cisplatin treatment for testicular cancer. Lancet 2000;355:1075-6.

[72] Clemens E, de Vries AC, Pluijm SF, et al. Determinants of ototoxicity in 451 platinum-treated Dutch survivors of childhood cancer: A DCOG late-effects study. Eur J Cancer. 2016;69:77-85.

[73] Katzenstein HM, Chang KW, Krailo M, et al; Children's Oncology Group. Amifostine does not prevent platinum-induced hearing loss associated with the treatment of children with hepatoblastoma: a report of the Intergroup Hepatoblastoma Study P9645 as a part of the Children's Oncology Group. Cancer. 2009;115:5828-35.

[74] Marina N, Chang KW, Malogolowkin M, et al; Children's Oncology Group. Amifostine does not protect against the ototoxicity of high-dose cisplatin combined with etoposide and bleomycin in pediatric germ-cell tumors: a Children's Oncology Group study. Cancer. 2005;104:841-7.

[75] Fouladi M, Chintagumpala M, Ashley D, et al. Amifostine protects against cisplatin-induced ototoxicity in children with average-risk medulloblastoma. J Clin Oncol. 2008;26(22):3749-55.

[76] Gurney JG, Bass JK, Onar-Thomas A, et al. Evaluation of amifostine for protection against cisplatin-induced serious hearing loss in children treated for average-risk or high-risk medulloblastoma. Neuro Oncol. 2014;16(6):848-55.

[77] Doolittle ND, Muldoon LL, Brummett RE, et al. Delayed sodium thiosulfate as an otoprotectant against carboplatin-induced hearing loss in patients with malignant brain tumors. Clin Cancer Res 2001;7:493-500.

[78] Muldoon LL, Pagel MA, Kroll RA, et al. Delayed administration of sodium thiosulfate in animal models reduces platinum ototoxicity without reduction of antitumor activity. Clin Cancer Res 2000;6:309-315.

[79] Neuwelt EA, Brummett RE, Doolittle ND, et al. First evidence of otoprotection against carboplatininduced hearing loss with a two-compartment system in patients with central nervous system malignancy using sodium thiosulfate. J Pharmacol Exp Ther 1998;286:77-84.

[80] Goel R, Cleary SM, Horton C, et al. Effect of sodium thiosulfate on the pharmacokinetics and toxicity of cisplatin. J Natl Cancer Inst 1989;81:1552-1560.

[81] Erdlenbruch B, Nier M, Kern W, Hiddemann W, Pekrun A, Lakomek M. Pharmacokinetics of cisplatin and relation to nephrotoxicity in paediatric patients. Eur J Clin Pharmacol 2001;57:393402.

[82] Harned TM, Kalous O, Neuwelt A, et al. Sodium thiosulfate administered six hours after cisplatin does not compromise antineuroblastoma activity. Clin Cancer Res 2008;14:533-540.

[83] Brock PR, Maibach R, Childs M, et al. Sodium thiosulfate for protection from cisplatin-induced hearing loss. N Engl J Med. 2018;378(25):2376-2385.

[84] Holdiness MR. Clinical pharmacokinetics of N-acetylcysteine. Clin Pharmacokinet 1991;20:123-34.

[85] Rumack BH, Bateman DN. Acetaminophen and acetylcysteine dose and duration: past, present and future. Clin Toxicol (Phila). 2012; 50( 2): 91- 8.

[86] Feghali JG, Liu W, Van De Water TR. L-n-acetyl-cysteine protection against cisplatin-induced auditory neuronal and hair cell toxicity. Laryngoscope 2001; 111: 1147-55.

[87] Sarafraz Z, Ahmadi A, Daneshi A. Transtympanic Injections of $\mathrm{N}$-acetylcysteine and Dexamethasone for Prevention of Cisplatin-Induced Ototoxicity: Double Blind Randomized Clinical Trial. Int Tinnitus J. 2018;22(1):40-5.

[88] Langer T, am Zehnhoff-Dinnesen A, Radtke S, Meitert J, Zolk O. Understanding platinum-induced ototoxicity. Trends Pharmacol Sci 2013; 34: 458-69. 